Supporting Information

\title{
Laser-Induced Patterned Photonic Crystal Heterostructure for Multimetal Ion Recognition
}

Lijing Zhang ${ }^{1}$, Bofan Liu ${ }^{1}$, Wenbo Yang ${ }^{1}$, Chong Li $^{1}$, Jiang Chun ${ }^{2}$, Rongfu Wen ${ }^{2}$, Shengyang $\mathrm{TaO}^{1 *}$

${ }^{1}$ Department of Chemistry, School of Chemical Engineering, Dalian University of Technology, Dalian 116024, P. R. China

E-mail: taosy@dlut.edu.cn

${ }^{2}$ Liaoning Key Laboratory of Clean Utilization of Chemical Resources, School of Chemical Engineering, Dalian University of Technology, Dalian 116024, P. R. China
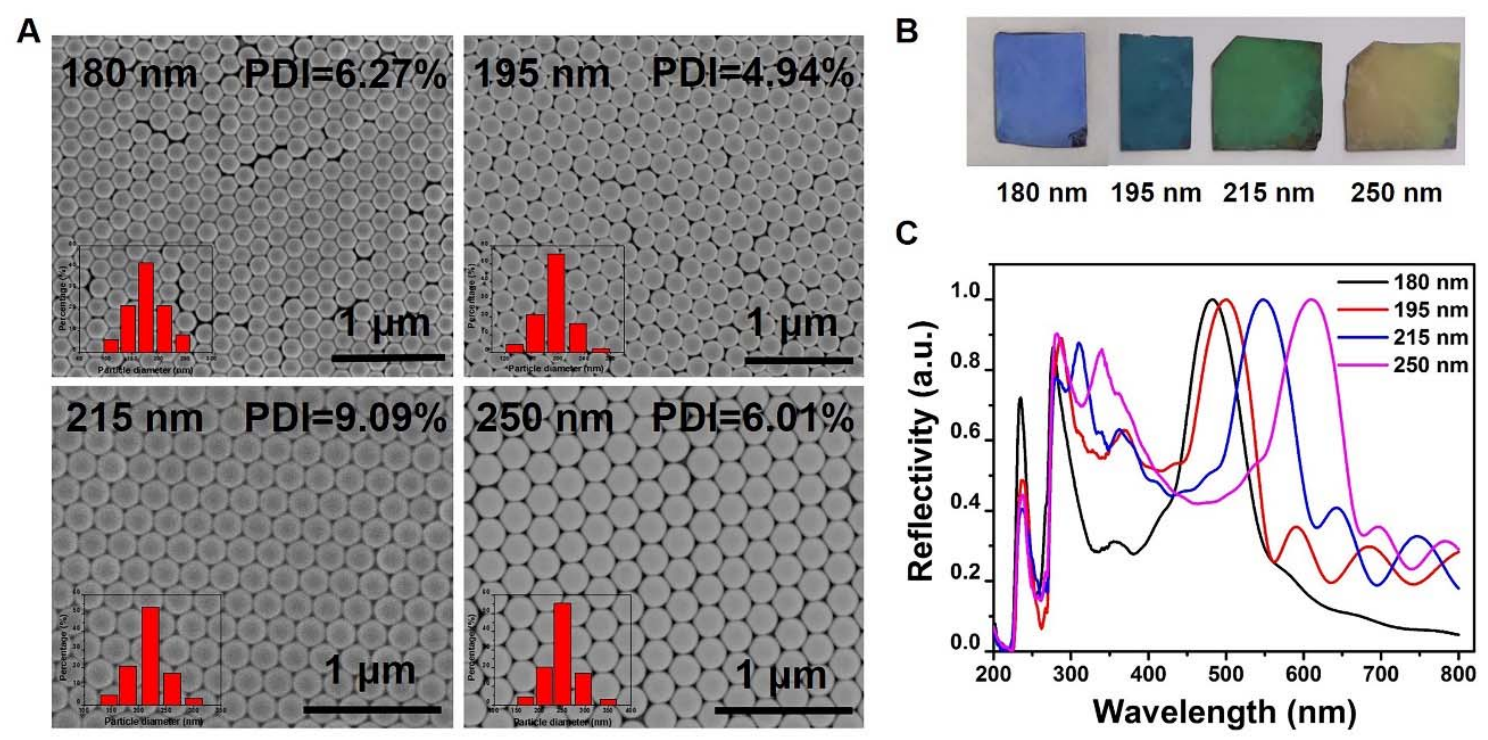

Figure S1. (A) The SEM images and corresponding particle size distribution of PS spheres selected in this work. (B) Photographs of the PC films (silicon wafer as substrate) prepared with different diameters of PS spheres. The PC films have obvious structural colors. (C) The normalincidence reflection spectra of series of homogeneous PC films. 

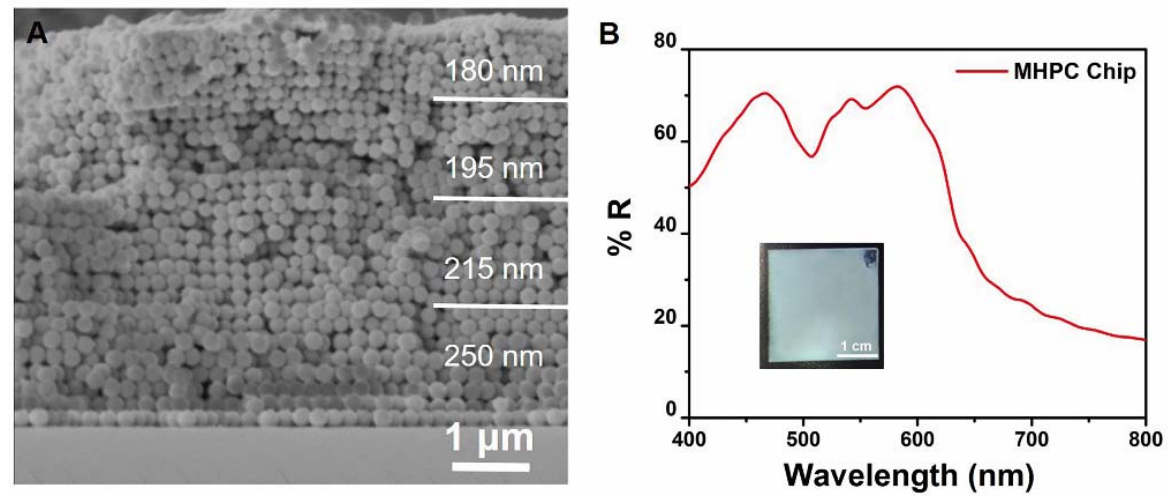

Figure S2. (A) Typical cross-sectional SEM images of MHPC. $(250 \mathrm{~nm}) 8 /(215 \mathrm{~nm})_{8} /(195$ $\mathrm{nm}) 8 /(180 \mathrm{~nm})_{8}$. (B) The normal-incidence reflection spectra of MHPC film.
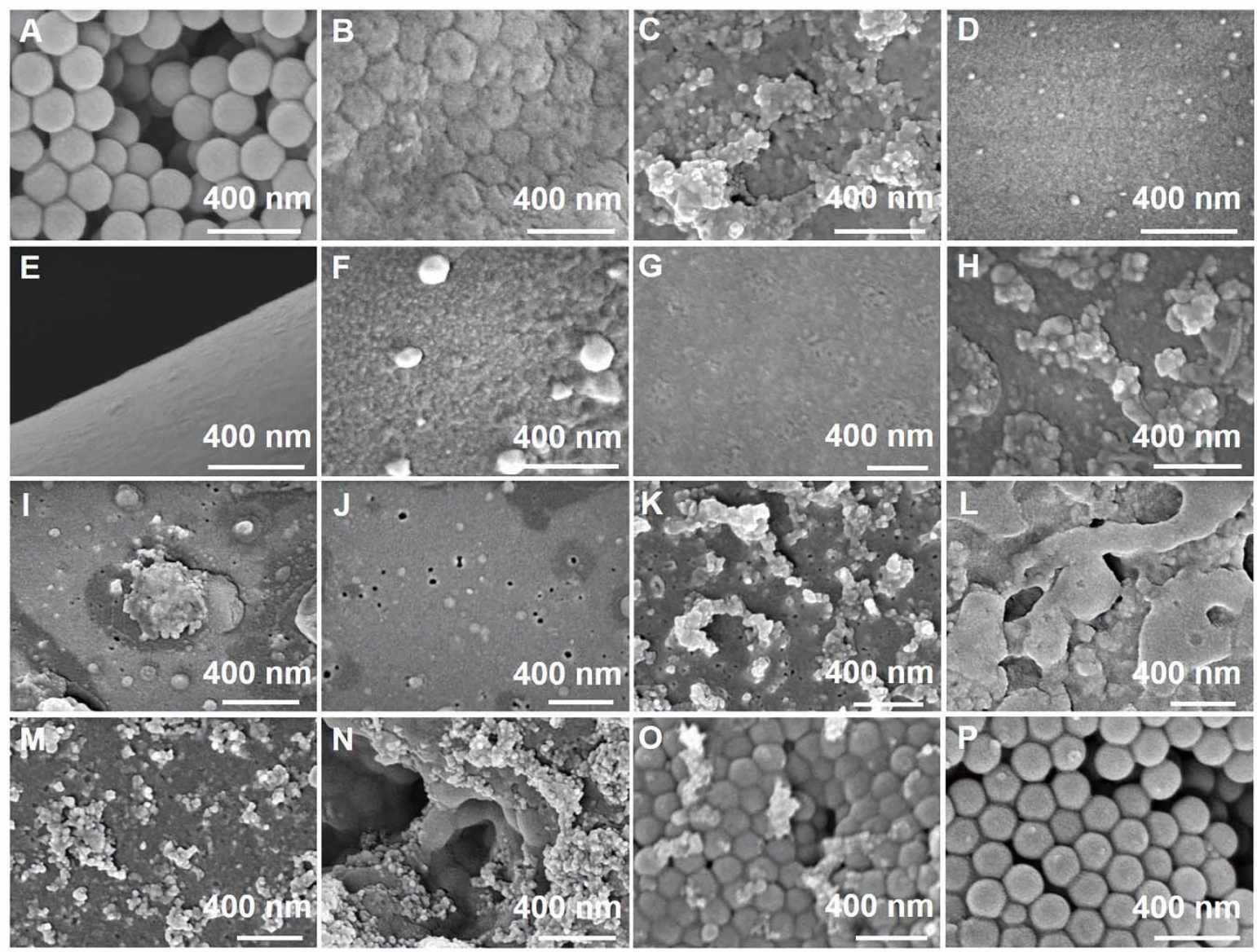

Figure S3. The SEM images of surface morphology change in laser sintered area in radial direction corresponding to the dash line in Figure 3B. 


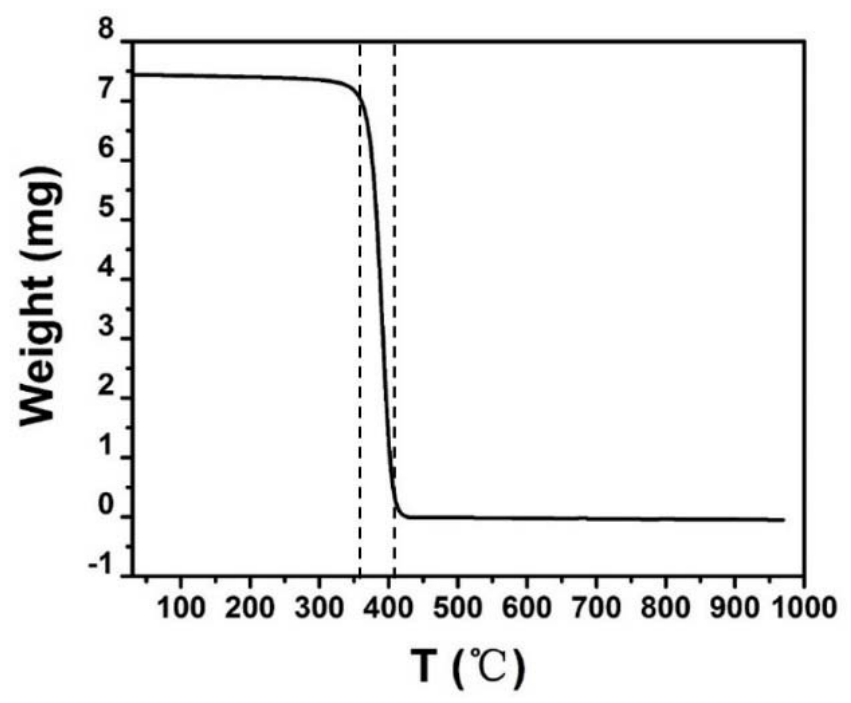

Figure S4. The T-G curve of PS spheres used in this work. The starting point of the carbonization temperature $\left(\mathrm{T}_{\mathrm{c}}\right)$ is about $360^{\circ} \mathrm{C}$.

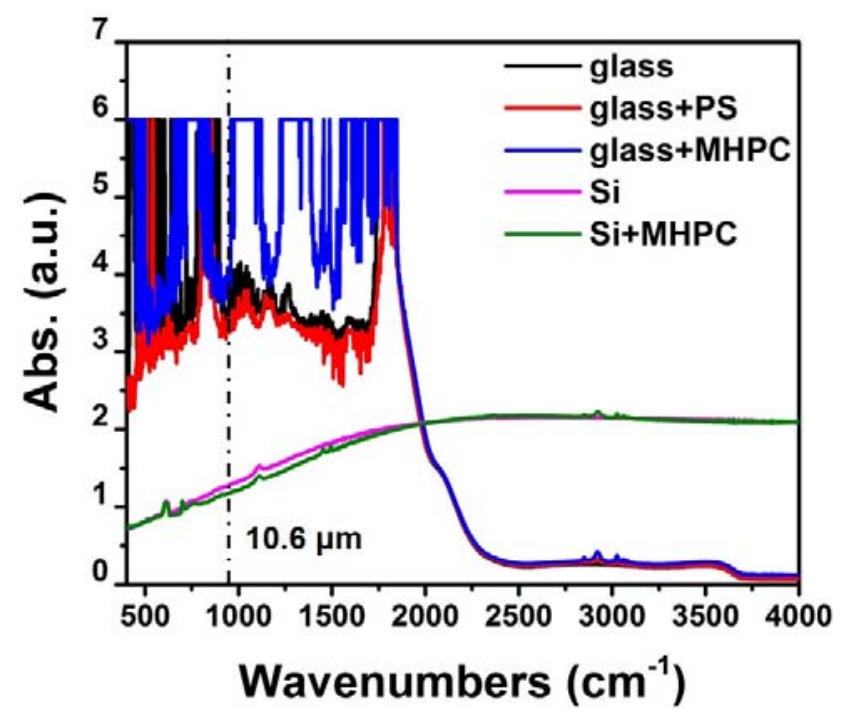

Figure S5. The IR absorption spectra of glass, glass with PS film, glass with MHPC, silicon wafer and silicon wafer with MHPC. 


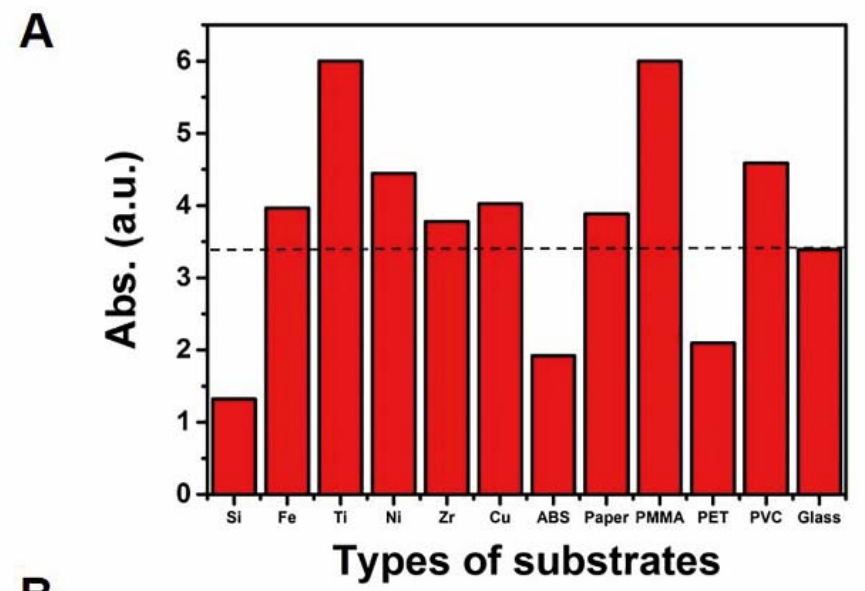

B

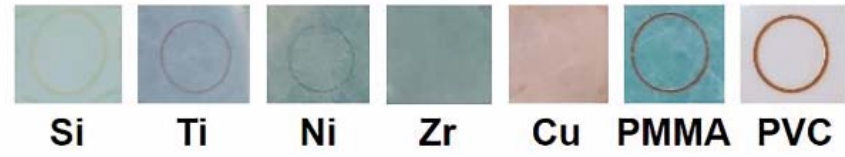

Figure S6. (A) The IR absorptivity of different substrates at $10.6 \mu \mathrm{m}$. (B) The patterning situation of PC on different substrates.

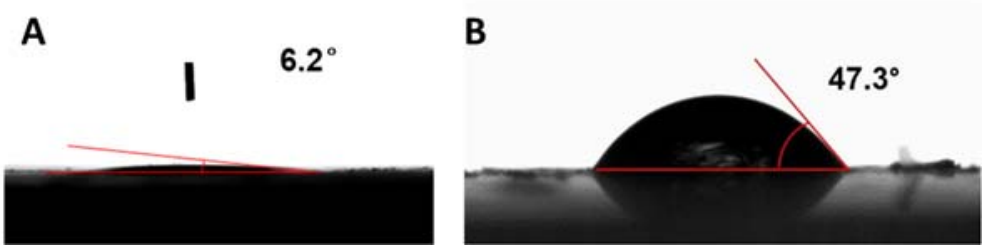

Figure S7. (A) The contact angle image of MHPC surface 3 months after oxygen plasma treatment. (B) The contact angle of $2 \mu \mathrm{L}$ droplet on a solid circle of $15 \mathrm{~W} \& 600 \mathrm{~mm} \mathrm{~s}^{-1}$. 


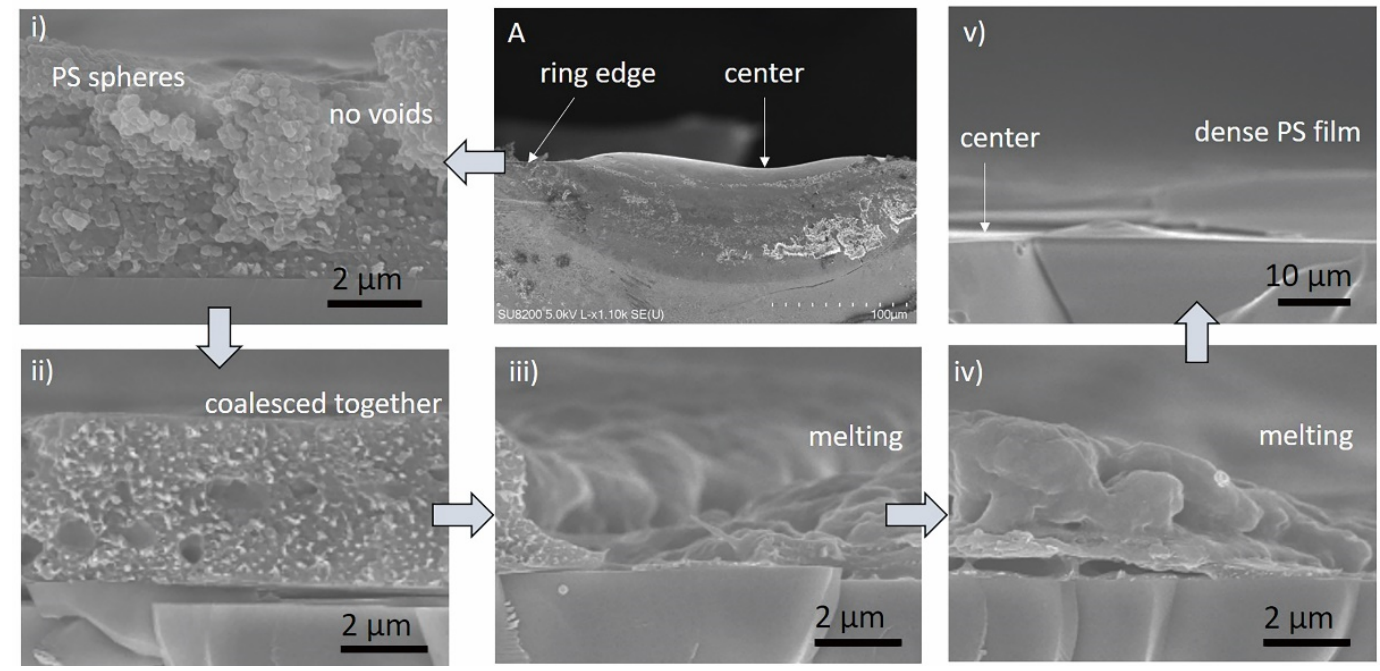

Figure S8. (A) The cross-sectional SEM image of the sintered ring shows a morphology of concavity in the middle and convex on both sides. i-v) The cross-sectional morphology evolution from ring edge to center.
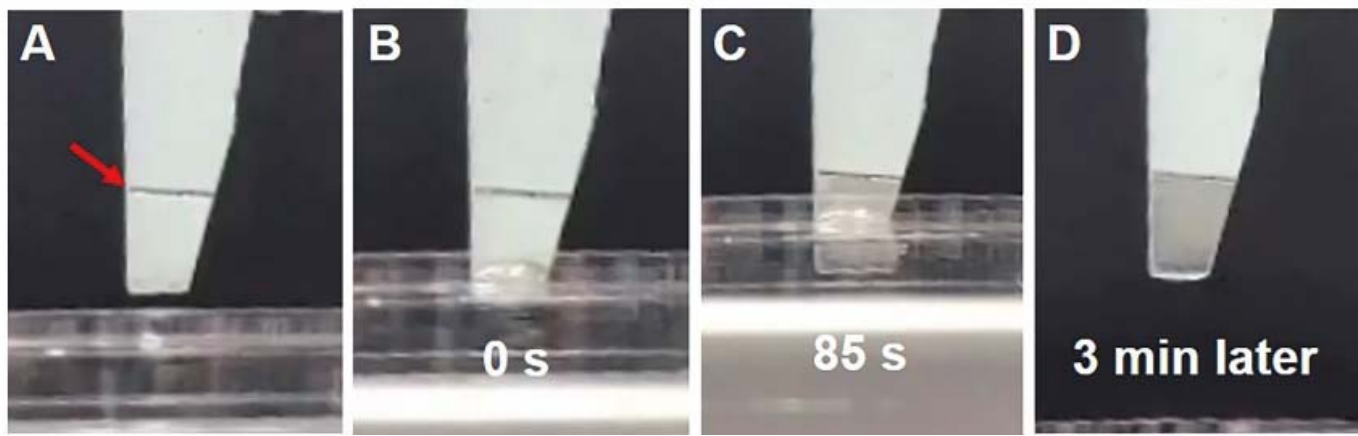

Figure S9. Capillary water absorption experiment: The surface of the super-hydrophilic MHPC chip is sintered a line pattern by direct laser writing $\left(15 \mathrm{~W} \& 600 \mathrm{~mm} \mathrm{~s}^{-1}\right)$. (A) The sample with a sintered line was placed up above a petri dish filled with water. (B) The sample with the sintered line is immersed in water and the liquid starts to infiltrate upward. (C) Photo image shows that water infiltrate up to the boundary of the sintered line. (D) Photo image show that water cannot climb over the sintered line even after 3 minutes. 

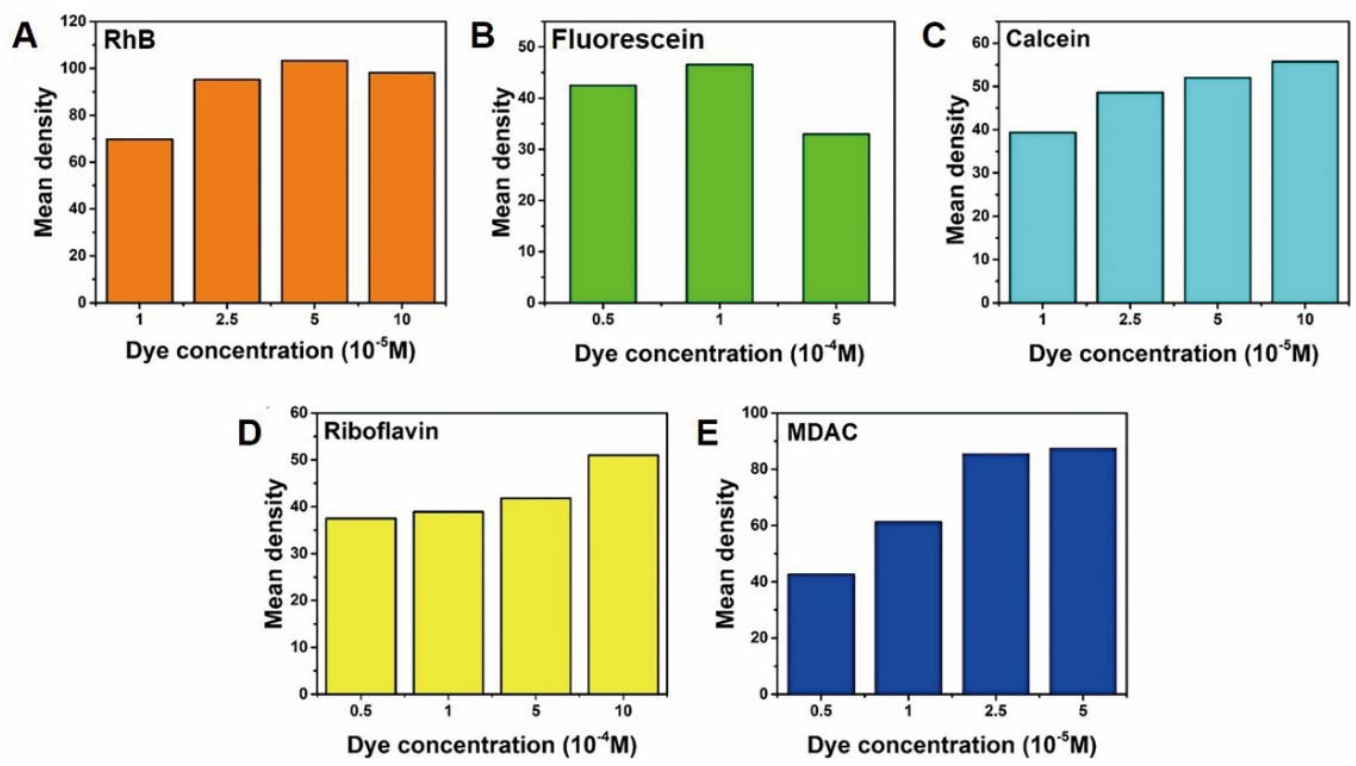

Figure S10. Fluorescence intensity of each kind of solution at different concentrations. (A) RhB, $5 \times 10^{-5}$ M. (B) Fluorescein, $1 \times 10^{-4}$ M. (C) Calcein, $1 \times 10^{-4}$ M. (D) Riboflavin $1 \times 10^{-3}$ M. (E) MDAC, $5 \times 10^{-5} \mathrm{M}$.

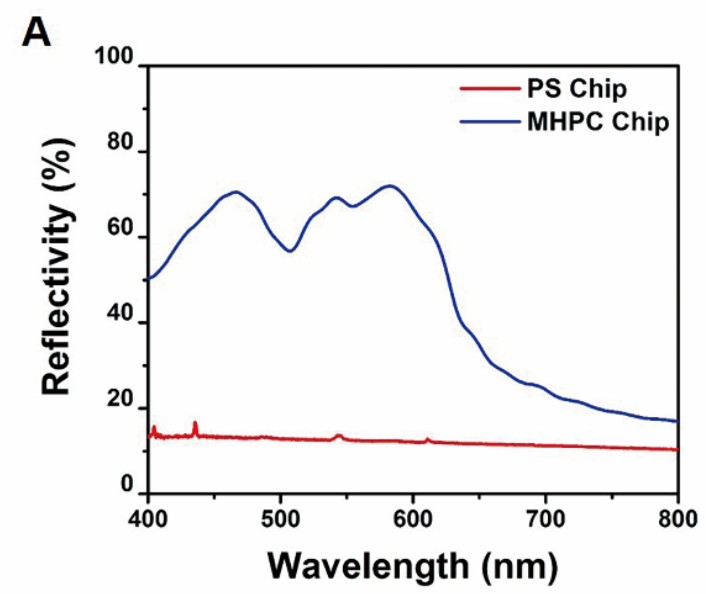

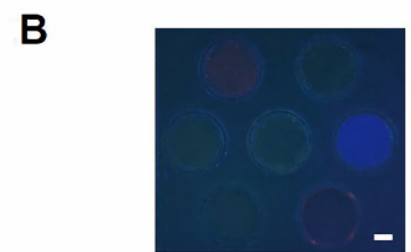

PS

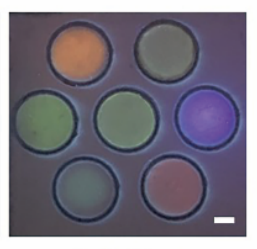

MHPC

Figure S11. (A) The normal-incidence reflection spectra of the MHPC film and PS film (no stopband). (B) Photograph of the fluorescence sensor array based on PS chip and MHPC chip, the scale bar is $1 \mathrm{~mm}$. The PS film here is fabricated by heating the MHPC chip to just lose its structural color to keep the consistency of parameters such as thickness and dye content. 


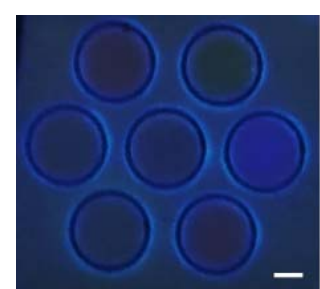

$\mathrm{pH}=3.5\left(\mathrm{Cr}^{3+}\right)$

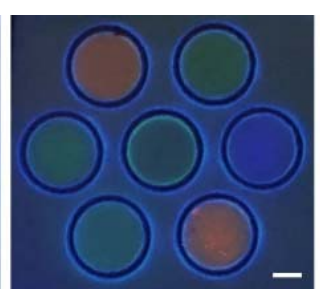

Control

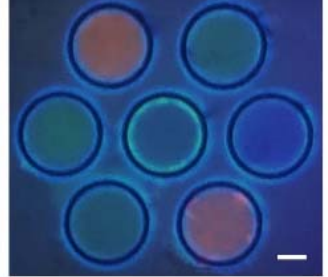

$\mathrm{pH}=3.5(\mathrm{NaOH} / \mathrm{HCl})$

Figure S12. Photograph of the experiment that proves the $\mathrm{pH}$ of the aqueous solution does not affect the testing results, the scale bar is $1 \mathrm{~mm}$.

Fluorescence image
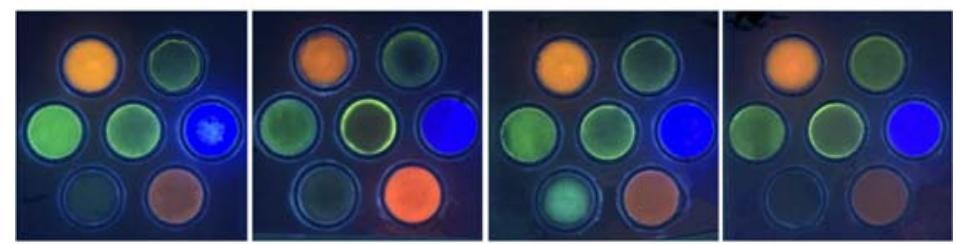

Control

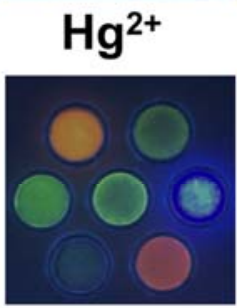

$\mathrm{Al}^{3+}$

$\mathrm{Pb}^{2+}$

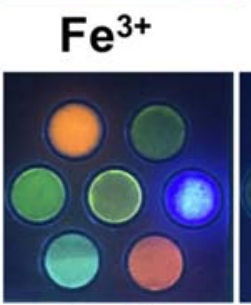

$\mathrm{Zn}^{2+}$
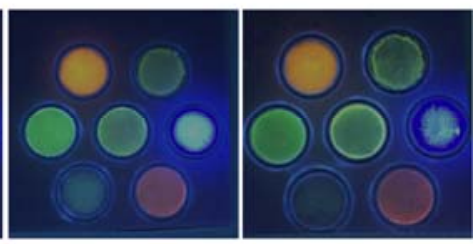

$\mathrm{Cd}^{2+}$

$\mathrm{Ba}^{2+}$
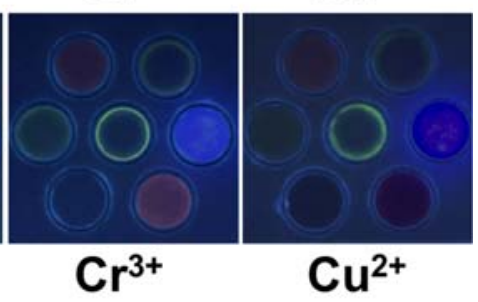

Figure S13. The fluorescence photos obtained by dropping 9 kinds of metal ion solutions on the MHPC chip. 


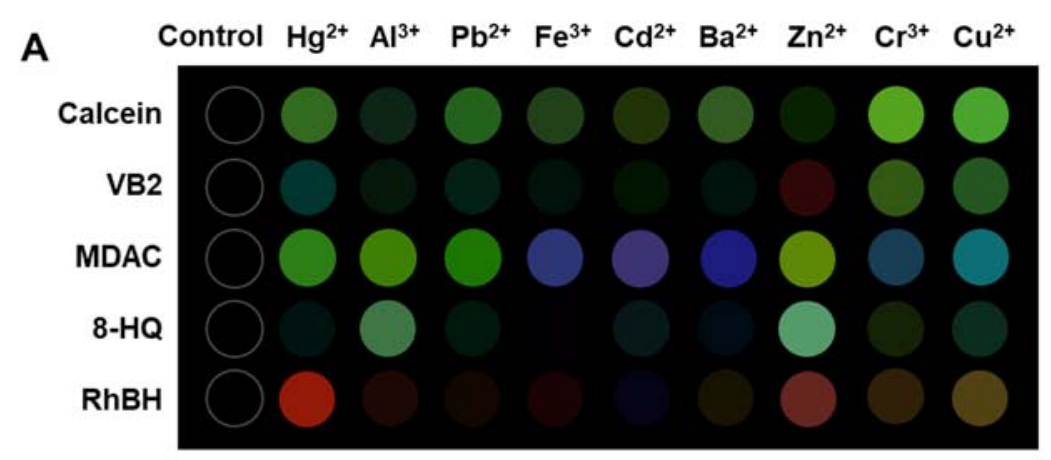

B

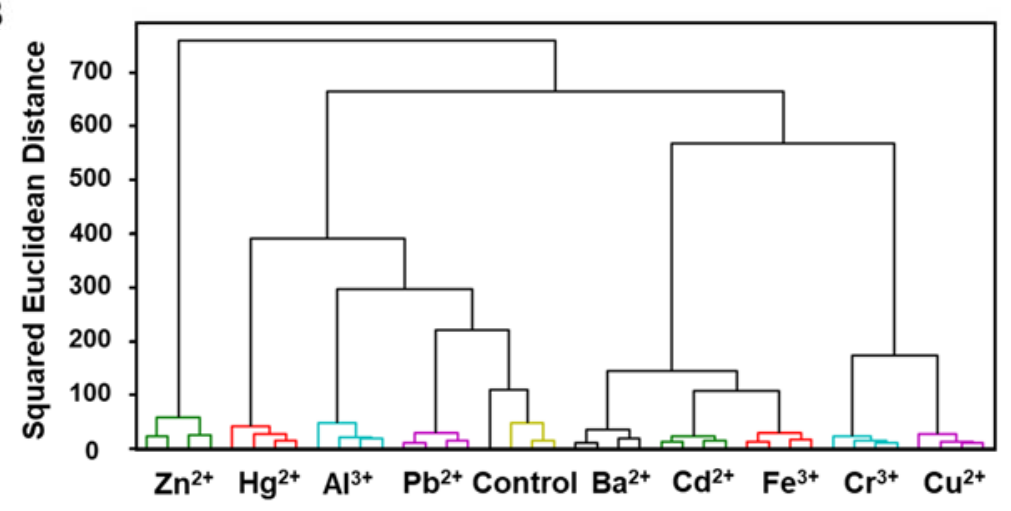

Figure S14. Fingerprints (A) and HCA results (B) obtained from part of the detection data of 9 samples with only 5 receptors, the metal ion concentration is $10^{-4} \mathrm{M}$.

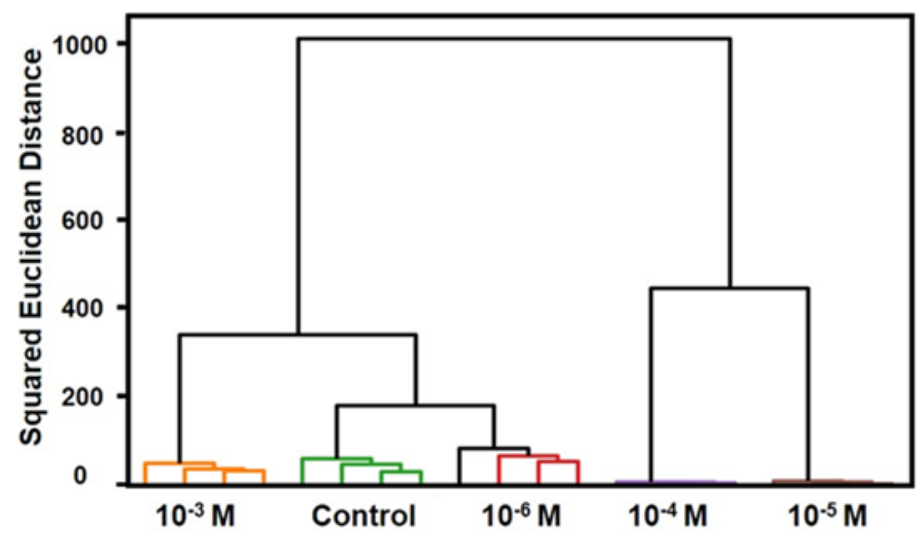

Figure S15. HCA results for $\mathrm{Zn}^{2+}$ at different concentrations. 
Table S1. The price parameters of the receptors selected in this work

\begin{tabular}{|c|c|c|c|c|}
\hline & & CAS\# & Structural formula & Price \\
\hline 1 & Rhodamine B & $81-88-9$ & & $\$ 0.14 / \mathrm{g}$ \\
\hline 2 & Fluorescein & $\begin{array}{l}2321- \\
07-5\end{array}$ & & $\$ 0.14 / \mathrm{g}$ \\
\hline 3 & Calcein & $\begin{array}{l}1461- \\
15-0\end{array}$ & & $\$ 1.39 / \mathrm{g}$ \\
\hline 4 & Riboflavin & $83-88-5$ & & $\$ 0.42 / \mathrm{g}$ \\
\hline 5 & 8-hydroxyquinoline & $\begin{array}{l}148-24- \\
3\end{array}$ & & $\$ 0.08 / \mathrm{g}$ \\
\hline 6 & $\begin{array}{l}\text { 7-Diethylamino-4- } \\
\text { methylcoumarin }\end{array}$ & $91-44-1$ & & $\$ 0.31 / \mathrm{g}$ \\
\hline 7 & Rhodamine B hydrazide & $\begin{array}{l}74317- \\
53-6\end{array}$ & & $\begin{array}{l}\text { Self- } \\
\text { synthesized }\end{array}$ \\
\hline
\end{tabular}


Table S2. The information on fluorescence emission wavelength of each receptor before and after combining with metal ions.

\begin{tabular}{lllllllllll}
\hline Receptors & Control & $\mathrm{Cr}$ & $\mathrm{Fe}$ & $\mathrm{Cd}$ & $\mathrm{Al}$ & $\mathrm{Ba}$ & $\mathrm{Zn}$ & $\mathrm{Cu}$ & $\mathrm{Hg}$ & $\mathrm{Pb}$ \\
\hline RhB & 581.0 & 581.0 & 581.0 & 581.0 & 580.0 & 581.0 & 581.0 & 581.0 & 590.0 & 589.0 \\
Fluorescein & 519.9 & 513.0 & 513.0 & 515.1 & 514.0 & 513.0 & 510.0 & 513.0 & 543.0 & 540.0 \\
Calcein & 516.0 & 507.0 & 506.1 & 508.0 & 508.0 & 507.0 & 508.9 & 508.9 & 508.0 & 508.9 \\
Riboflavin & 521.1 & 525.0 & 523.0 & 523.0 & 525.0 & 525.0 & 522.0 & 526.1 & 523.9 & 527.0 \\
8-HQ & & - & - & - & 518.0 & - & 505.0 & - & - & - \\
MDAC & 468.9 & 471.1 & 466.1 & 470.0 & 468.9 & 468.0 & 463.9 & 467.0 & 465.5 & 466.4 \\
RhBH & 581.0 & 586.0 & 591.9 & 591.0 & 587.1 & 591.0 & 589.0 & 590.0 & 601.0 & 581.0 \\
\hline
\end{tabular}

Movie S1. Video of the droplet spreading process on patterned surface taken by the high-speed camera.

Movie S2. Video of the droplet spreading process on open surface taken by the high-speed camera.

Movie S3. Video of the capillary absorption experiment taken by the cell phone.

Movie S4. Video of the contact angle variation of 5 drops with time taken by the high-speed camera. 